\title{
Current Perspectives on the Role of Captopril Imaging in the Diagnosis of Renovascular Disease
}

\author{
KATHRYN A. COLLINS, M.D., and RICHARD J. GUSBERG, M.D.
}

\begin{abstract}
As the population ages, renal artery stenosis has been increasingly detected among patients with refractory hypertension and/or renal dysfunction. There is a need for a safe, simple, reliable, cost-effective method for detecting clinically significant renal artery stenoses in patients who will benefit from revascularization. The asymmetric renal response to angiotensin converting enzyme inhibition in the setting of renal artery stenosis is the basis for several diagnostic techniques that screen patients with suspected renal artery stenoses to determine functional significance. Captopril renal scintigraphy is the most widely applied, however, ACE inhibition in conjunction with ultrasound and magnetic resonance are the focus of the most recent research. This review focuses primarily on the physiologic basis, indications, techniques and utility of captopril renal scintigraphy. Newer captopril imaging methods are introduced and consideration given to practical issues such as cost and risk/benefit analysis.
\end{abstract}

Keywords Captopril, renal artery, radioisotope renography

As our population ages, renal artery stenosis has been increasingly detected among patients with refractory hypertension and/or renal dysfunction. The evaluation and management of these often high-risk, elderly atherosclerotic patients poses significant challenges: How can clinically relevant renal artery lesions be detected most safely and reliably? If the goal is to prolong life or prevent dialysis dependence, how can we predict reliably these outcomes? And, how can we best select patients for interventions, recognizing that failed interventions in this population come at significant human and financial cost (whether they fail because the intervention is inadequate or because the renal lesion was not causative)? There is clearly a need for a safe, simple, reliable,

K.A.C., Vascular Fellow, Section of Vascular Surgery, Yale University School of Medicine, New Haven, CT; R.J.G., Professor of Surgery, Section of Vascular Surgery, Department of Surgery, Yale University School of Medicine, New Haven, CT.

Copyright (C) 2000 by Thieme Medical Publishers, Inc., 333 Seventh Avenue, New York, NY 10001, USA.

Tel. +1 (212) 584-4662. 0894-8046,p;2000,13,1,43,70,ftx,en;pvs000084 
cost-effective method for detecting clinically significant renal artery stenoses in patients who will benefit from successful revascularization.

In 1983, Hricik et al postulated a disturbance in the autoregulation of glomerular filtration as a mechanism in a series of 11 patients with worsened renal function as a result of having received antihypertensive therapy with angiotensin converting enzyme (ACE) inhibitors. ${ }^{1}$ The asymmetric renal response to ACE inhibition seen in the setting of renal artery stenosis became the basis for the development of several diagnostic techniques to screen for renovascular hypertension (RVH). The most useful of these continues to be captopril renal scintigraphy (CRS). Since its introduction, the role of CRS in the diagnosis of renovascular hypertension has been debated largely because of a wide variability reported in the literature with respect to its diagnostic sensitivity, specificity, and predictive value. Much of the controversy centers not on the virtues of captopril scintigraphy but on what constitutes a hemodynamically significant renal artery stenosis, what defines renovascular hypertension, and what defines a cure following intervention. In the context of the current definitions, this review will focus on the physiologic basis, indications, techniques, and utility of CRS as well as new insights gained since the American Society for Hypertension held a consensus conference on captopril renography in Cleveland, Ohio in $1990 .^{2}$

\section{HYPERTENSION, RENAL ARTERY STENOSIS AND RENOVASCULAR HYPERTENSION}

It is estimated currently that 60 million Americans are hypertensive. ${ }^{3}$ Hypertension is defined as a systolic blood pressure $>140 \mathrm{mmHg}$ or a diastolic blood pressure $>90 \mathrm{mmHg}$ taken on more than one occasion. ${ }^{4}$ Of the surgically correctable causes of hypertension, a renovascular etiology is the most common but is found in only a small percentage (3 to 5\%) of the total hypertensive population. ${ }^{5}$ While some degree of renal artery narrowing can be identified in many patients with atherosclerosis, not all renal artery stenoses are hemodynamically and clinically significant. ${ }^{6}$ The more severe the stenosis, the more likely it is to result in impaired renal blood flow with resultant hypertension and/or ischemic nephropathy. ${ }^{7}$ However, a presumed diagnosis of either renovascular hypertension or ischemic nephropathy cannot be proven until an intervention, either angioplasty (with or without a stent) or surgery, results in an improvement in blood pressure and/or renal function. Setaro suggested a classification for renal artery lesions based on the degree of stenosis, presence of hypertension, and/or renal dysfunction and the response to intervention. ${ }^{8}$ The important features of this classification are shown in Table 1.

An ideal screening test for renovascular hypertension would not only identify the presence of a critical renal artery lesion but also determine its functional significance and predict the outcome of intervention. Characteristics of 
Table 1 Classification of Renal Artery Lesions

\begin{tabular}{|c|c|c|c|c|}
\hline & $\begin{array}{l}\text { Degree of } \\
\text { Stenosis }\end{array}$ & $\begin{array}{l}\text { Blood } \\
\text { Pressure }\end{array}$ & Renal Function & $\begin{array}{l}\text { Response to } \\
\text { Treatment }\end{array}$ \\
\hline Silent RAS & Subcritical* & Normal & Normal & $\mathrm{N} / \mathrm{A}$ \\
\hline $\begin{array}{l}\text { Ischemic } \\
\text { nephropathy }\end{array}$ & Critical & Normal & Impaired * * & $\begin{array}{l}\text { Potential } \\
\text { improvement } \\
\text { in renal func- } \\
\text { tion with } \\
\text { with revascular- } \\
\text { ization }\end{array}$ \\
\hline $\begin{array}{l}\text { Renovascular } \\
\text { hypertension }\end{array}$ & Critical & Hypertension & $\begin{array}{l}\text { May or may } \\
\text { not be } \\
\text { impaired }\end{array}$ & $\begin{array}{l}\text { Cure or improve- } \\
\text { ment in blood } \\
\text { pressure***; } \\
\text { potential } \\
\text { improvement } \\
\text { of renal dys- } \\
\text { function }\end{array}$ \\
\hline Anatomic RAS & Critical & Hypertension & $\begin{array}{l}\text { May or may } \\
\text { not be impaired }\end{array}$ & No improvement \\
\hline
\end{tabular}

RAS $=$ Renal artery stenosis.

*A subcritical lesion is defined as less than $60 \%$ diameter reduction; critical $>60 \%$ diameter reduction.

${ }^{*}$ Renal insufficiency is defined as a creatinine greater than $1.5 \mathrm{mg} / \mathrm{dL}$.

$* * *$ A cure is defined as normal blood pressure (systolic blood pressure $<140 \mathrm{mmHg}$ and diastolic blood pressure $<90 \mathrm{mmHg}$ ) on no blood pressure medications; an improvement is defined as normal blood pressure on fewer medications than prior to intervention.

Source: Setaro JF, Saddler MC, Chen CC, et al. Simplified captopril renography in diagnosis and treatment of renal artery stenosis. Hypertension 1991;18:289-298. Used with permission.

such a test are listed in Table 2. Regardless of whether it would be feasible to screen all individuals with hypertension or renal insufficiency for functional arterial lesions it would be neither cost- nor time-efficient because the preva-

Table 2 Ideal Screening Test
Simple
Reliable
Inexpensive
Reproducible
Sensitive
Specific
Unaffected by renal dysfunction
Independent screen of each kidney
Able to predict outcome to intervention 
lence of renovascular disease is so low in these populations. The ideal population to screen is one in which the prevalence of the disease is neither very low nor very high. ${ }^{9}$ The prevalence of renovascular hypertension increases from $1 \%$ in the general population of hypertensives to between 10 and $50 \%$ in populations with well-defined clinical criteria. ${ }^{8,10}$ In addition, the predictive value of any test is enhanced when used to screen a population with this increased prevalence. ${ }^{9}$ The validity of any screening test requires a consistent definition of the disease state to be screened. The definitions of the population to be screened and a successful outcome impact substantially on its statistical merit. While there is considerable variability reported on the results of CRS, when applied to an appropriately-selected, high-risk population of hypertensives, CRS has been demonstrated to be a screening test for renovascular hypertension with a reasonably high sensitivity, specificity, positive predictive, and negative predictive values. The role of captopril testing in patients with ischemic nephropathy has not been determined.

\section{ETIOLOGY OF RENAL ARTERY STENOSIS}

The two most common causes of renovascular hypertension are atherosclerosis and fibromuscular dysplasia. Other less common etiologies include Takayasu's aortitis, congenital anomalies including AV malformations or fistulas, neurofibromatosis, extrinsic obstruction of the renal artery, congenital coarctation of the abdominal aorta, renal artery thrombosis or embolism, and radiation injury. ${ }^{11}$

Fibromuscular dysplasia (FMD) is identified in approximately $30 \%$ of patients with renovascular hypertension. Multiple pathologic types have been identified with medial fibroplasia comprising 60 to $85 \%$ of these lesions. ${ }^{12,13}$ Predominantly young white women are affected and it occasionally occurs bilaterally or may also affect other arteries as well. The classic appearance on contrast angiography is one of a string of beads in the mid-renal artery with or without mural aneurysms. Progression occurs over time in one third of affected arteries but total occlusion and renal loss are rare. ${ }^{7}$ Perimedial fibroplasia constitutes 15 to $25 \%$ of fibromuscular dysplasias. ${ }^{13}$ These lesions are more aggressive and progressive stenoses are more common. Intimal fibroplastic lesions are infrequent ( 1 to $2 \%$ ). ${ }^{13}$

Atherosclerosis is the etiology of renovasular hypertension in at least $70 \%$ of cases. ${ }^{3}$ In contrast to FMD, atherosclerotic renal artery lesions occur in much older individuals. Like FMD these lesions are seen predominantly in caucasians, with men outnumbering women $2: 1$. The vast majority $(80 \%)$ of patients who present with atherosclerosis as the cause of renovascular hypertension have generalized atherosclerosis which may involve the abdominal aorta, coronary, cerebral, or peripheral circulations. ${ }^{11}$ Focal renal artery stenoses may, however, exist without clinical evidence of generalized athero- 
sclerosis in approximately 15 to $20 \%$ of patients. ${ }^{11}$ Atherosclerotic renal artery lesions, when compared to FMD, are more likely to progress $(44 \%$ compared with $33 \%$ ) and are more likely to occlude (16\% compared with $0 \%){ }^{7}$ The risk of progression is particularly high in those lesions identified with a greater than $75 \%$ stenosis at initial diagnosis and occlusion often occurs within 2 years. ${ }^{7}$ Progressive stenosis may be associated with worsening hypertension, worsened renal function or, in the case of bilateral disease or a single kidney, renal failure requiring dialysis. The need for safe and accurate screening is particularly compelling in elderly patients for whom the risks associated with both diagnosis and treatment are increased.

While the clinical presentation can suggest the possibility of a renal artery lesion, history and physical examination alone are neither sensitive nor specific. ${ }^{14} \mathrm{~A}$ combination of demographic criteria, response to anti-hypertensive therapy, and physical evidence of generalized atherosclerotic disease are useful in identifying a patient at a high risk for a renovascular lesion and may indicate the need for further testing. The criteria recognized by the consensus group are given in Table 3 . In addition, the presence of angiospastic retinopathy, hemorrhage or exudates on fundoscopic examination (Grade III or Grade IV retinopathy), is indicative of severe hypertension and associated with a $43 \%$ prevalence of renovascular hypertension. ${ }^{15}$ The finding of a small kidney by any prior investigational procedure may also support the diagnosis. Once a high-risk patient is identified, screening for renovascular disease should be initiated.

\section{Table 3 Patient Risk Factors for Renovascular Hypertension}

Diastolic blood pressure $>105$

Longstanding and well controlled hypertension which becomes refractory to an existing regimen and has no other explanation

Clinical evidence of generalized vascular disease* and significant hypertension

Hypertension and abdominal bruits

Hypertension and elevated creatinine when no other etiology can be found to explain the renal dysfunction

Age under 25 with development or severe hypertension with diastolic BP > 105 especially if white and not obese

Refractory hypertension on adequate three drug antihypertensive regimen and no other etiology can be found

Patients with hypertension who develop new or more severe renal failure when treated with ACE inhibitors.

*Any one of: peripheral vascular disease, cerebrovascular disease, aortic occlusive disease, abdominal aortic aneurysms, and coronary artery disease.

Source: Black HR et al. Report of the working party group for patient selection and preparation. AJH: 1991;4:S745-S746. Used with permission. 


\section{DETECTION OF RENOVASCULAR DISEASE}

Multiple methods of testing have been used to identify the presence of a renal artery lesion. Modalities can be categorized broadly into those that define an anatomic lesion and those that determine functional significance. Historically, intravenous pyelogram (IVP), split renal function studies with or without captopril, plasma renin assay (PRA), and standard renogram (no captopril) have been used; however, their sensitivities for detecting renovascular disease were too low to be useful as screening tests and they have since been abandoned. Renal vein renin sampling has been associated with a high specificity but a low sensitivity and is not applicable in all patients or available at all centers. Currently, conventional angiography, captopril renal scintigraphy, duplex scanning, and magnetic resonance imaging/angiography (MRI/MRA) are the predominant screening methods used in patients with clinically suspected renovascular disease. ACE inhibition in conjunction with ultrasound and magnetic resonance imaging are the focus of the most recent research. The sensitivities and specificities and other pertinent information for each of these modalities are given in Table 4. Functional testing relies on the detection of perfusion-related alterations in renal physiology. Knowledge of the reninangiotensin-aldosterone system and the physiologic effect of ACE inhibition in unilateral, bilateral and single kidney renal artery stenosis are essential to the understanding of captopril renography and are reviewed below.

\section{PHYSIOLOGY OF RENOVASCULAR HYPERTENSION}

Significant constriction of the main renal artery leads to a cascade of physiologic events that may cause the development of hypertension and/or chronic renal ischemia. The clinical symptomatology depends on the nature of the disease process, time-course of the progression of the stenosis, compensatory response of both the kidney ipsilateral and contralateral to the stenosis as well as the development of collateral flow channels. The models used to study the physiology of renovascular hypertension induce acute or variably chronic renal artery stenoses and have provided much information regarding the alterations in the renin-angiotensin-aldosterone axis and body fluid and sodium balance. ${ }^{16}$ The physiologic alterations seen in the idealized one-clip and two-clip models of Goldblatt renovascular hypertension are representative of the majority of cases of renovascular hypertension seen in clinical practice. The complexities of the chronic adaptive response especially in the development of bilateral renal artery stenoses have not been fully elucidated, however.

Angiotensin II (ATII) is produced via a cascade in response to decrements in glomerular perfusion pressure (Fig. 1). ATII has four major effects: (1) stimulation of aldosterone secretion by the glomerulosa cells of the adrenal cortex; (2) vasoconstriction of the systemic and renal arterioles to increase 
Table 4 Testing for Renovascular Disease

\begin{tabular}{|c|c|c|c|c|c|c|}
\hline & $\begin{array}{l}\text { Anatomic } \\
\text { Testing }\end{array}$ & $\begin{array}{l}\text { Functional } \\
\text { Testing }\end{array}$ & $\begin{array}{l}\text { Bilateral } \\
\text { Disease }\end{array}$ & ${ }^{*} \operatorname{Sens}(\%)$ & ${ }^{*}$ Spec(\%) & Comments \\
\hline $\begin{array}{l}\text { Renal vein } \\
\text { renin** }\end{array}$ & - & +++ & - & 74 & 100 & $\begin{array}{l}\text { Invasive, } \\
\text { difficult prepar- } \\
\text { ation, need to } \\
\text { withhold antih- } \\
\text { pertensive med- } \\
\text { ications }\end{array}$ \\
\hline $\begin{array}{l}\text { Captopril } \\
\text { Renography* }\end{array}$ & + & ++ & $+/-$ & $\begin{array}{l}\text { RAS: } 89 \\
\text { RVH: } 90\end{array}$ & $\begin{array}{l}\text { RAS: } 92 \\
\text { RVH: } 86\end{array}$ & $\begin{array}{l}\text { May predict the } \\
\text { outcome to } \\
\text { intervention }\end{array}$ \\
\hline Angiography & +++ & - & + & RAS: 100 & RAS: 100 & $\begin{array}{l}\text { Gold standard for } \\
\text { RAS, invasive, } \\
\text { expensive, Option } \\
\text { for immediate } \\
\text { intervention }\end{array}$ \\
\hline Duplex * * & ++ & - & + & 85 & 90 & $\begin{array}{l}\text { Up to } 15 \% \text { tech- } \\
\text { nical failures }\end{array}$ \\
\hline $\mathrm{MRA}^{* *}$ & +++ & - & + & $\begin{array}{l}87 \\
67\end{array}$ & $\begin{array}{l}97 \\
-\end{array}$ & $\begin{array}{l}\text {-Prox } 3.5 \mathrm{~cm} \mathrm{RA} \\
\text {-All locations } \\
\text { Poor with distal } \\
\text { and segmental } \\
\text { lesions }\end{array}$ \\
\hline
\end{tabular}

${ }^{*}$ Sensitivity/specificity from prospective studies which include outcome to intervention.

**Without captopril challenge.

RAS = Renal artery stenosis; RVH = Renovascular hypertension .

Data from: Blaufox MD et al. Cost efficacy of the diagnosis and therapy of renovascular hypertension. J Nucl Med 1996;37:171-177. King BF. Diagnostic imaging evaluation of renovascular hypertension. Abdominal Imaging 1995;20:395-405. Debatin J et al., Imaging of the renal arteries: value of MR angiography. AJR 1991;157:981-990. Used with permission.

blood pressure; (3) stimulation of $\mathrm{ADH}$ secretion from the posterior pituitary and stimulation of the thirst center within the hypothalamus; and (4) enhancement of $\mathrm{NaCl}$ resorption by the proximal tubule. ${ }^{17}$ The vasoconstrictive effect of ATII in the kidney is such that the efferent arteriole is constricted preferentially greater than the afferent arteriole to maintain an appropriate gradient for glomerular filtration (Fig. 2). ${ }^{18}$ The effects of circulating ATII are not confined to the kidney ipsilateral to the stenosis; glomerular filtration in the contralateral kidney is increased, as is effective renal plasma flow in response to increased blood pressure. Both kidneys develop shifts in their pressure-natriuresis relationship in which a new set point for sodium homeostasis is attained. ${ }^{19}$

ACE inhibitors block the conversion of the decapeptide angiotensin I to the octapeptide angiotensin II suppressing its vasoconstrictive, volume-and- 


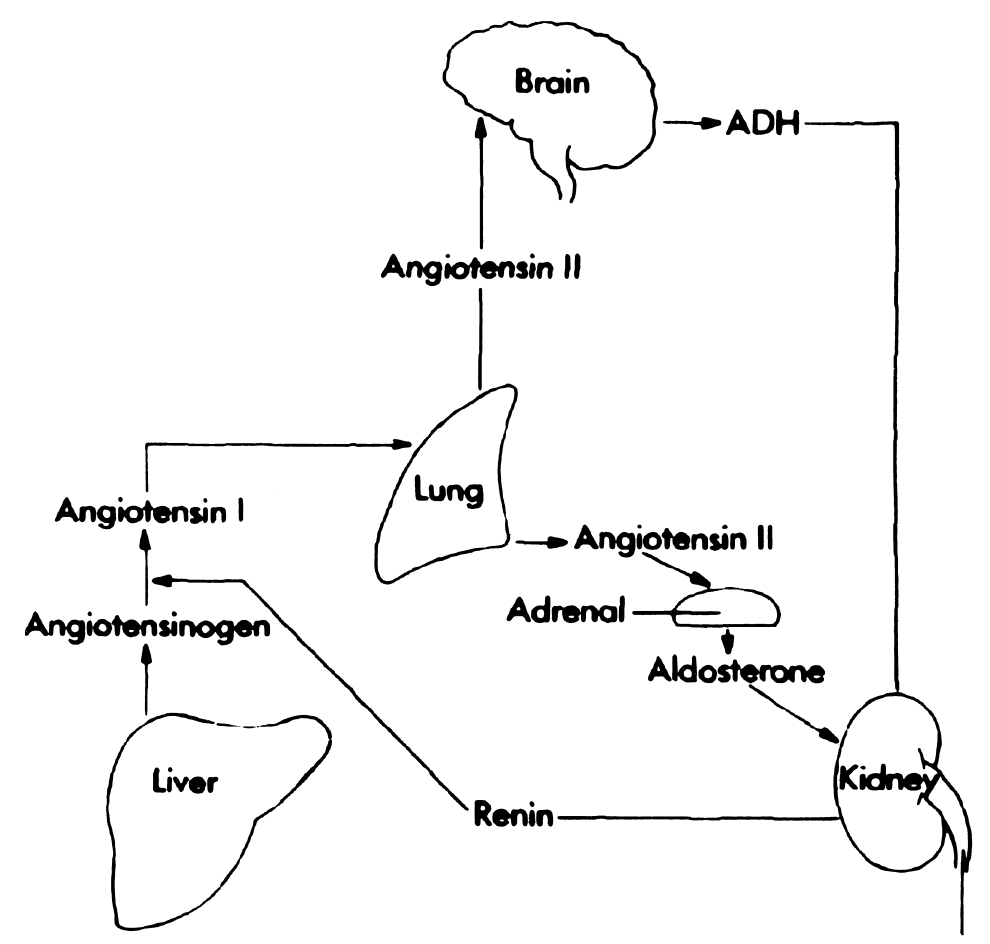

Fig. 1 Renin-angiotensin-aldosterone axis. Reproduced with permission from Stanton BA, Koeppem BM. Control of body fluid osmolality and volume. In: Berne RM, Leve MN, eds. Physiology, St Louis, MO: Mosby; 1993:719-753

salt retaining actions. Because of the differential effects of ACE inhibition between the ipsilateral and contralateral kidneys, ACE inhibition is a pharmacologic probe that has been used extensively to investigate the basic physiology of renovascular disease.

With unilateral renal artery stenosis, a mild stenosis will be compensated by the activity of the renin-angiotensin-aldosterone system with little change in the perfusion pressure or glomerular filtration rate (GFR) in the ipsilateral kidney. If the stenosis is significant, however, filtration may suffer. ${ }^{20}$ Because of the induced hypertensive state and the effects of circulating ATII, the contralateral kidney will experience an increased GFR, effective renal plasma flow (ERPF), and urine flow thereby maintaining volume homeostasis. With ACE inhibition and the consequent loss of vasomotor tone in the efferent arteriole, there is a decrease in perfusion pressure and the ipsilateral kidney experiences a pressure-associated decrease in GFR, urine flow, and salt excretion compared to its baseline state. ${ }^{19}$ The contralateral kidney has a dramatically increased GFR, urine flow, and salt excretion suggesting vasodilation presumably from the reduction in vasoconstrictor effect of circulating ATII. ${ }^{21}$ 
Table 5 Physiologic Effects With and Without ACE Inhibition

\begin{tabular}{cllll}
\hline & GFR & ERPF & Urine vol & Salt Excretion \\
\hline $\begin{array}{c}\text { Without ACE-I } \\
\text { Clipped* }\end{array}$ & N,D & N,D & $\mathrm{N}^{* *}$ & $\mathrm{~N}^{* *}$ \\
$\begin{array}{c}\text { Unclipped } \\
\text { With ACE-I }\end{array}$ & $\mathrm{I}$ & $\mathrm{I}$ & $\mathrm{I}$ & $\mathrm{I}$ \\
$\begin{array}{c}\text { Clipped } \\
\text { Unclipped }\end{array}$ & $\mathrm{D}$ & $\mathrm{D}$ & $\mathrm{D}$ & $\mathrm{D}$ \\
& $\mathrm{I}$ & $\mathrm{I}$ & $\mathrm{I}$ & $\mathrm{I}$ \\
\hline
\end{tabular}

*Depends on the severity of the stenosis with decrements seen in severe stenosis.

${ }^{* *}$ May be decreased with a solitary kidney or severe bilateral stenosis.

$\mathrm{GFR}=$ glomerular filtration rate; $\mathrm{ERPF}=$ Effective renal plasma flow; $\mathrm{N}$ = normal; $\mathrm{I}=$ increased; $\mathrm{D}=$ decreased.

Source: Nally JV, Black HR. State of the art review: Captopril renography-pathophysiological considerations and clinical observation. Sem Nucl Med 1992;22:85-97. Used with permission.

These changes are reversible and not present when nonspecific blood pressure agents are used.

With bilateral stenoses, one kidney will behave more 'clipped' than the other depending on the relative severity of the lesions from one side to the other. The ability of a functional test to detect a relative difference between the two sides may be impaired if the differences between the kidneys are not disparate enough.

A renal artery stenosis to a single kidney results in volume-dependent rather than renin-dependent hypertension. In the absence of the 'unclipped' kidney no compensation exists to prevent volume expansion and the degree of hypertension is not solely dependent on renin but on the alterations in sodium and fluid balance as well. The response to ACE inhibition may also be more dependent on sodium balance. Some investigators have disputed the notion that single kidney renal artery stenosis is purely volume dependent and have argued that functional testing remains worthwhile in this subset of patients. ${ }^{22}$ The physiologic alterations produced by renal artery stenosis with and without ACE inhibition are summarized in Table 5. The exaggerated difference in GFR and ERPF between the 'clipped' and 'unclipped' kidneys following ACE inhibition forms the basis for captopril renography.

\section{CAPTOPRIL RENOGRAPHY}

Renal scintigraphy has been performed since the 1950s to analyze comparative differences in renal function. The calculation of divided renal function was made possible with the introduction of computer systems, however, the specificity of the test for renovascular disease was too low and the exam was 
largely abandoned. ${ }^{23}$ The recognition that captopril-induced alterations in renal perfusion that could potentially enhance its sensitivity as a screening test was suggested by Majd et al. in 1983. ${ }^{24}$ Multiple studies in animal models confirmed the validity of this approach and the evaluation of human subjects by captopril scintigraphy was initiated in the mid-1980s with initial focus on methodology. ${ }^{8,25-31}$ Table 6 lists the major events leading to the development of captopril renography. The selection of radionuclide and criteria for diagnosis were scrutinized in these early studies to optimize the sensitivity and specificity of the test and, later, research validated CRS as a predictor of outcome in response to intervention. ${ }^{29,32-35}$

Table 6 History of Renovascular Hypertension and Captopril Renography

\begin{tabular}{|c|c|c|}
\hline Year & Author & Advance \\
\hline 1836 & Bright & Clinical association between hypertension and renal disease \\
\hline 1897 & $\begin{array}{l}\text { Tigerstedt \& } \\
\text { Bergman }\end{array}$ & Renin discovered \\
\hline 1934 & Goldblatt & Renovascular hypertension decribed in dog model \\
\hline 1954 & Freeman & $\begin{array}{l}\text { First cure of renovascular hypertension in humans by rena } \\
\text { artery thromboendarterectomy }\end{array}$ \\
\hline 1956 & Smith & $\begin{array}{l}\text { Experience reviewed with nephrectomy; only } 26 \% \text { cure rate } \\
\text { of hypertension }\end{array}$ \\
\hline 1956 & Taplin & Developed nuclide renography \\
\hline 1940 & $\begin{array}{l}\text { Page \& } \\
\text { Helmes }\end{array}$ & Elucidation of renin-angiotensin-aldosterone system \\
\hline \multirow[t]{2}{*}{1964} & $\begin{array}{l}\text { Howard \& } \\
\text { Conner }\end{array}$ & Split renal function studies \\
\hline & & Captopril introduced as an anti-hypertensive \\
\hline 1982 & Gates & Calculation of divided renal function from scinitgraphy \\
\hline 1983 & Hricik & $\begin{array}{l}\text { Proposed mechanism of renal dysfunction in patients treated } \\
\text { with ACE inhibitors }\end{array}$ \\
\hline 1983 & Majd & $\begin{array}{l}\text { Suggested captopril prior to renography to increase } \\
\text { sensitivity }\end{array}$ \\
\hline 1987 & $\begin{array}{l}\text { Geykses } \\
\text { et al. }{ }^{25}\end{array}$ & $\begin{array}{l}\text { Suggested captopril renogram may distinguish functional } \\
\text { from anatomic RAS }\end{array}$ \\
\hline $\begin{array}{l}1987- \\
1989\end{array}$ & & Early studies established safety and efficacy of CRS \\
\hline 1989 & $\begin{array}{l}\text { Meier } \\
\text { et al. }{ }^{32}\end{array}$ & $\begin{array}{l}\text { Captopril renogram shown to be a predictor of outcome of } \\
\text { intervention }\end{array}$ \\
\hline 1990 & $\begin{array}{l}\text { Setaro } \\
\quad \text { et al. }\end{array}$ & $\begin{array}{l}\text { Simplified Captopril Renogram-eliminated need to } \\
\text { discontinue antihypertensive except ACE inhibitor }\end{array}$ \\
\hline 1990 & & $\begin{array}{l}\text { American Society of Hypertension Consensus Conference } \\
\text { on CRS held in Cleveland, Ohio }\end{array}$ \\
\hline
\end{tabular}

Source: Dean RH, Hansen K. Renovascular hypertension. In: Moore WS, ed. Vascular Surgery-A comprehensive review. Philadelphia, PA: W.B. Saunders; 1998:521-541. Used with permission. 
The test is performed with the intravenous administration of a radiopharmaceutical. The time course of its activity through the kidney is measured with a gamma camera and time-activity curves are generated. The procedural protocol recommended by the consensus group is summarized in Table 7.

\section{Radiopharmaceuticals}

The radiopharmaceuticals used in CRS consist of a radionuclide coupled to a localizing agent. Iodine $131\left({ }^{131} \mathrm{I}\right)$, Iodine $123\left({ }^{123} \mathrm{I}\right)$ and Technetium $99 \mathrm{~m}(99 \mathrm{~m} \mathrm{Tc})$ are the radionuclides that have been used to label orthoiodohippurate $(\mathrm{OIH})$, diethylenetriaminepenta-acetic acid (DTPA) or mercaptoacetyl-triglycine (MAG3) to form either [ $\left.{ }^{131} \mathrm{I}\right] \mathrm{OIH},\left[{ }^{123} \mathrm{I}\right] \mathrm{OIH}$, [99m Tc]DTPA, or [99m Tc]MAG3. These radiopharmaceuticals can be classified as glomerular $\left(\left[{ }^{99 m} \mathrm{mc}\right] \mathrm{DTPA}\right)$ or tubular $\left(\left[\begin{array}{ll}131 & \mathrm{I}\end{array}\right] \mathrm{OIH},\left[{ }^{123} \mathrm{I}\right] \mathrm{OIH}\right.$, [99m Tc]MAG3) depending on their renal handling. ${ }^{36}$ The radiation dose and imaging characteristics of the radiopharmaceutical impact on the safety and reliability of the test. The imaging qualities of technetium are considered to be superior to the iodinated nuclides but until the recent introduction of MAG3, tubular agents were coupled to only iodinated agents. Iodine 131

Table 7 Protocol for Captopril Renal Scintigraphy

Before testing

- Cessation of ACE inhibitors 7-14 days prior

- Cessation of diuretics 1-3 days prior

- May remain on all other anti-hypertensives and medications*

- Oral hydration at home with two glasses of water prior to arriving

At testing

- Have the patient drink 300-500 cc water or juice in the department* *

- Place IV

- Measure urine specific gravity on initial void, record urine volumes throughout the study and replace orally

- Monitor blood pressure every 15 minutes

- Administer Captopril $25 \mathrm{mg}$ recommended (optional $50 \mathrm{mg}$ ) or Enalaprilat $.04 \mathrm{mg} / \mathrm{kg}$ not to exceed $2.5 \mathrm{mg}$ total dose

- If hypotension; administration of IV fluid

- Perform study

- Perform baseline study next day if captopril renogram positive***

*Verapamil and cyclosporin may have effects.

${ }^{* *}$ Hydration is mandatory, because a low urine flow will cause a slow decrease of the excretion phase in the contralateral kidney making interpretation difficult.

${ }^{* * *}$ One day protocol: Perform baseline study first and follow with the captopril challenge at least 6 hours later.

Sources: Black HR et al. Report of the working party group for patient selection and preparation. AJH 1991;4:S745-S746. Blaufox MD, et al. Report of the working party group on determining the radionuclide of choice. AJH 1991;4:S747-S748. Used with permission. 
requires an excessive dose of radiation and is no longer used for CRS. The major features of these radiopharmaceuticals used in CRS are found in Table 8. No significant differences in CRS sensitivity or specificity have been identified to date between the use of either [ $\left.{ }^{99 \mathrm{~m}} \mathrm{Tc}\right] \mathrm{DTPA}$ or [99m Tc]MAG3. 37

$[99 \mathrm{~m} \mathrm{Tc}] \mathrm{DTPA}$ is the most widely studied agent used in CRS. It is filtered exclusively by the glomerulus and is neither secreted nor absorbed by the tubules; it provides an accurate estimation of glomerular filtration rate (GFR), though, because it is slightly bound (10 to $15 \%$ ) to plasma proteins, and it underestimates GFR slightly. ${ }^{36}$ Because of its glomerular handling, it may not be the agent of choice in patients with significant renal dysfunction.

[99m Tc]MAG3 is a tubular agent that has largely replaced the use of $\left[{ }^{131} \mathrm{I}\right] \mathrm{OIH}$ and $\left[{ }^{123} \mathrm{I}\right] \mathrm{OIH}$. This radiopharmacautical is cleared primarily by the proximal tubules $(95 \%)$ with minimal filtration (5\%). ${ }^{36}$ The clearance of [99m Tc]MAG3 can be used to estimate ERPF. Because its extraction efficiency is greater than that of $[99 \mathrm{~m} \mathrm{Tc}] \mathrm{DTPA}$ it allows for better renal visualization and more satisfactory imaging in patients with impaired renal function. ${ }^{36,37}$ However, patients with renal dysfunction may also demonstrate increased hepatobiliary activity for this pharmaceutical and the appearance of [99m Tc] MAG3 in the gallbladder may impact on imaging of the right kidney.

\section{Diagnostic Criteria}

Renal scintigraphy can be used to assess renal function and anatomy with a variety of methods including renal perfusion imaging, renal function imaging, and analysis of time-activity (renogram) curves both before and after the administration of captopril.

Renal perfusion is assessed in the first minutes following the injection of the radiopharmaceutical. The bolus is seen in the proximal aorta with images

Table 8 Comparison of Radiopharmaceuticals in Renal Scintigraphy

\begin{tabular}{lllll}
\hline & Filtration Mechanism & Radiation Dose & Half Life & Image Quality \\
\hline 99mTc-DTPA & $\mathrm{G}$ & $\mathrm{I}^{*}$ & $6 \mathrm{~h}$ & $\mathrm{G}$ \\
123I-OIH & $\mathrm{T}>\mathrm{G}$ & $\mathrm{I}$ & $8 \mathrm{~d}$ & $\mathrm{I}$ \\
131 I-OIH & $\mathrm{T}>\mathrm{G}$ & $\mathrm{H}$ & $13 \mathrm{~h}$ & $\mathrm{P}$ \\
99mTc-MAG & $\mathrm{T}>\mathrm{G}$ & $\mathrm{L}$ & $6 \mathrm{~h}$ & $\mathrm{E}$ \\
& & & & \\
\hline
\end{tabular}

$\mathrm{G}=$ glomerular, $\mathrm{T}=$ tubular.

$\mathrm{L}=$ low, $\mathrm{I}=$ intermediate, $\mathrm{H}=$ high.

$\mathrm{P}=$ poor, $\mathrm{G}=$ good, $\mathrm{E}=$ excellent.

* May increase with renal dysfunction.

Adapted with permission from Mettler FA, Guiberteau MJ. Genitourinary system. In: Essentials of

Nuclear Imaging. Philadelphia, PA: W.B. Saunders; 1998:335-368. Used with permission. 


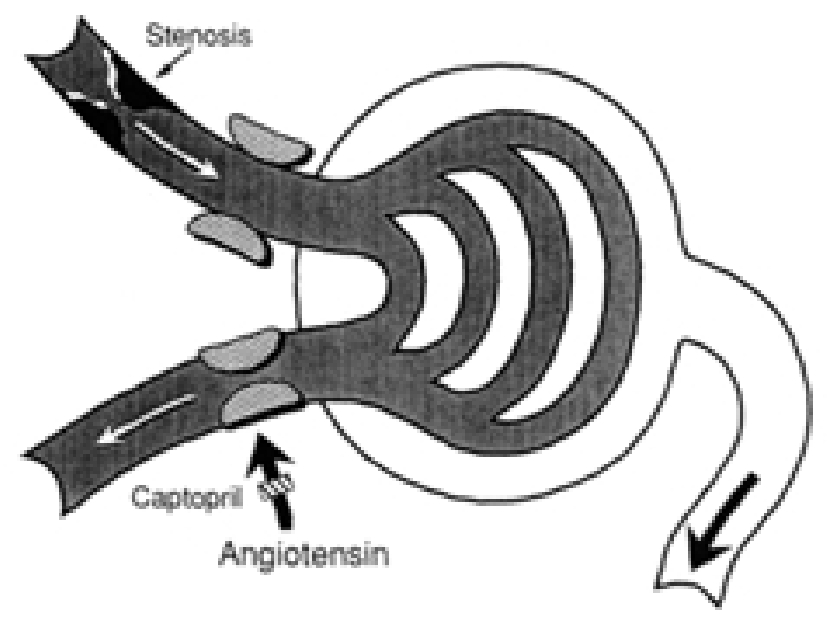

Fig. 2 Glomerulus and action of captopril. Inhibition of efferent sphincter tone by captopril results in loss of transglomerular filtration. Reproduced with permission from Meier GM, Sumpio B, Black HR, et al. Captopril renal scintigraphy: An advance in the detection and treatment of renovascular hypertension. J Vasc Surg 1990;11:770-777. Used with permission.

taken every 1 to 5 seconds. Activity in the kidneys is normally visualized within seconds after the bolus reaches the abdominal aorta. Symmetry and timing of renal perfusion can be assessed on the static images and renal size estimated as well. Time-activity curves for each kidney may be generated and compared to the time-activity curve of the abdominal aorta to assess relative renal perfusion.

Renal function imaging begins at the end of the renal perfusion sequence. Images are obtained every 3 to 5 minutes. Kidney anatomy, position, symmetry, function, and patency of the collecting system are assessed. Timeactivity curves for each kidney are likewise generated and the activity of one kidney relative to the other either before or after captopril administration is evaluated.

The renogram can be divided into three phases: (1) a vascular phase; (2) a concentration phase; and (3) a clearance phase (Fig. 3). ${ }^{36}$ The vascular transit phase usually lasts 30 to 60 seconds and is seen as an initial sharp rise. The cortical or tubular concentration phase exhibits a slower rise because renal accumulation of the radiopharmaceutical and ends in a peak occurring usually within 6 minutes. The clearance phase, caused by renal excretion, is seen as the downslope of the curve and is dependent on the patency of the renal outflow tract. Multiple parameters can be derived from the renogram including time to peak activity $\left(\mathrm{T}_{\mathrm{p}}\right)$, relative renal uptake ratio, half-time excretion, and differential residual cortical activity (RCA). Table 9 describes these parameters and gives normal values. In addition, GFR ([99m Tc $]$ DTPA) 


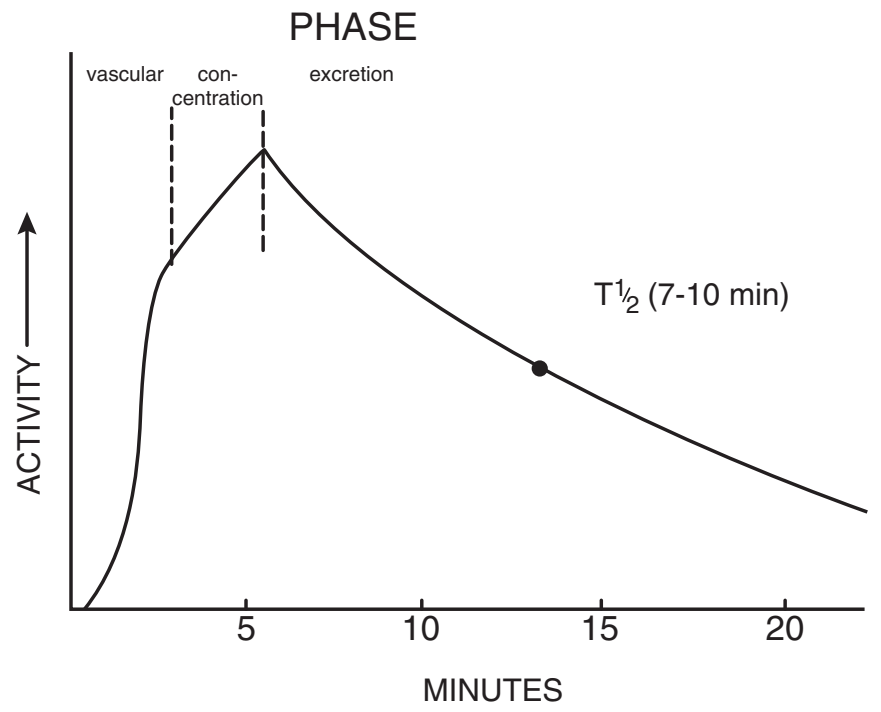

Fig. 3 Renogram phases. See text for description. Reproduced with permission from Mettler FA, Guiberteau JM. Genitourinary system. In: Essentials of Nuclear Imaging. Philadelphia, PA: WB Saunders; 1998:335-368. Used with permission.

Table 9 Normal Values for Renogram Parameters

\begin{tabular}{|c|c|c|c|}
\hline Parameter & Definition & Normal & Abnormal \\
\hline $\mathrm{Tp}$ & Time to peak activity & $<6$ minutes & $>6$ minutes \\
\hline $\begin{array}{l}\text { Relative renal uptake ratio } \\
\text { (2-3 mins })\end{array}$ & $\begin{array}{l}\text { Index of function } \\
\text { from one kidney to } \\
\text { the other at } 2-3 \\
\text { minutes }\end{array}$ & $50 \%$ & $\begin{array}{l}<40 \% \text { in } \\
\text { one kidney } \\
\text { is abnormal }\end{array}$ \\
\hline Half time excretion & $\begin{array}{l}\text { Time for half the } \\
\text { peak activity to be } \\
\text { cleared }\end{array}$ & $7-10$ mins & $>10$ mins \\
\hline $\begin{array}{l}\text { Residual cortical activity } \\
\text { (RCA) (15 mins) }\end{array}$ & $\begin{array}{l}\text { Percent of retained } \\
\text { activity at } 15 \\
\text { minutes expressed } \\
\text { relative to } \\
\text { peak activity }\end{array}$ & $\begin{array}{l}\text { Percentages } \\
\text { should be } \\
\text { equal }\end{array}$ & $\begin{array}{l}>20 \% \\
\text { difference } \\
\text { between } \\
\text { the kidneys }\end{array}$ \\
\hline $\begin{array}{l}\text { Maximal count ratio } \\
\quad(20 \mathrm{~min})\end{array}$ & $\begin{array}{l}\text { Activity at } 20 \\
\text { minutes relative to } \\
\text { peak activity }\end{array}$ & $<.3$ & $>.3$ \\
\hline
\end{tabular}

Adapted with permission from Mettler FA, Guiberteau MJ. Genitourinary system. In: Essentials of Nuclear Imaging. Philadelphia, PA: WB Saunders; 1998:335-368. 
Table 10 Grading of Captopril Renogram

\begin{tabular}{lllll}
\hline Grade & Upslope & Tmax & Excretory phase & Kidney size \\
\hline & Normal & $<6$ & Normal & Normal \\
1 & Mild delay & $6-11$ & $+/-$ & Normal \\
$2 \mathrm{~A}$ & Delay & $>11$ & + & $+/-$ Decrease \\
$2 \mathrm{~B}$ & Delay & $>11$ & - & $+/-$ Decrease \\
3 & Reduction of uptake & NA & NA & $+/-$ Decrease \\
\hline
\end{tabular}

$\mathrm{NA}=$ not applicable.

Reproduced with permission from Nally JV, Chen C, Fine E, et al. Diagnostic criteria of renovascular hypertension with captopril renography—a concensus statement. AJH 1991;4:S749-S752.

and ERPF ([99m Tc]MAG3) can be estimated with either a plasma samplebased clearance or a camera based clearance method and the ratio between the kidneys obtained as a split function index.

The renogram also offers qualitative information that is useful. Based on a grading system initially proposed by Oei et al., the consensus group adopted the grading system shown in Table 10 with representative curves in Figure $4.38,39$ The shape of the renogram can be compared between kidneys as well as before and after the administration of captopril. The probability that a patient has a significant renal artery lesion causing hypertension is given as low, intermediate, or high depending on the change in grade before and after captopril (Table 11). An example of an abnormal captopril renogram is shown in Figure 5. In this patient, the time to peak activity dramatically increased changing a Grade 1 to a Grade $2 \mathrm{~A}$ renogram. The patient was found to have significant right orificeal renal artery stenosis. A normal renogram after captopril makes the presence of a hemodynamically significant renal artery stenosis unlikely and precludes the need to perform a baseline study. ${ }^{30,39}$ Little difference in sensitivity or specificity has been demonstrated with the use of qualitative renogram grading compared with the use of the quantitative parameters listed above. 38,40 The consensus group strongly encouraged the use of the grading system, however, a combination of grading plus quantitative parameter use continues to be used in many centers.

\section{CAPTOPRIL IMAGING: PAST, PRESENT AND FUTURE}

At the time of the consensus conference, a large degree of variability existed with respect to study design, patient selection, patient preparation, choice of radiopharmaceutical, choice of ACE inhibitor, drug dosage, degree of arterial stenosis to be identified, and outcome analysis. These early studies focused on methodology to identify techniques and diagnostic criteria that enhanced 
A
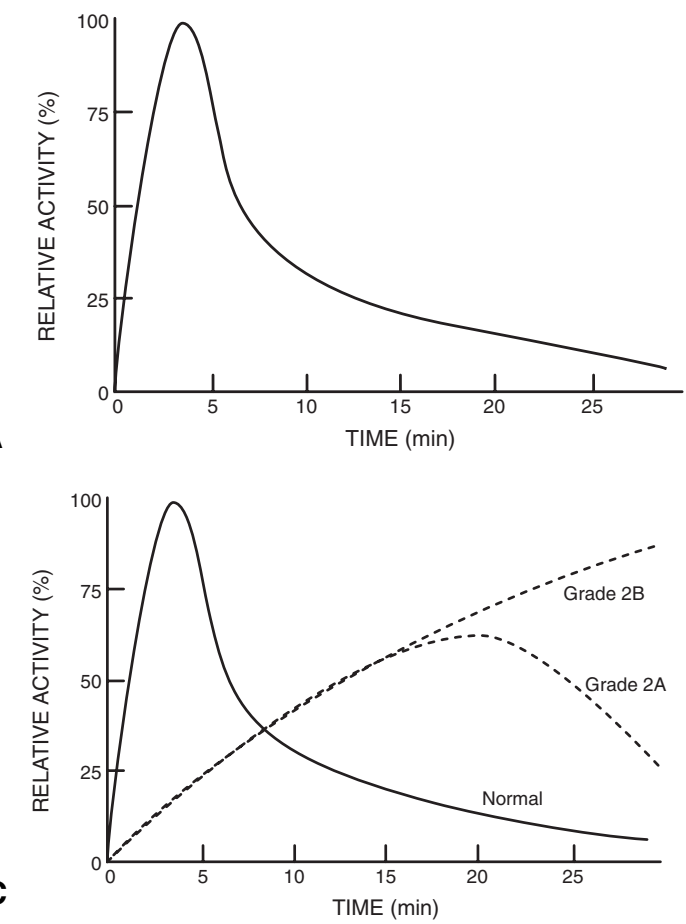
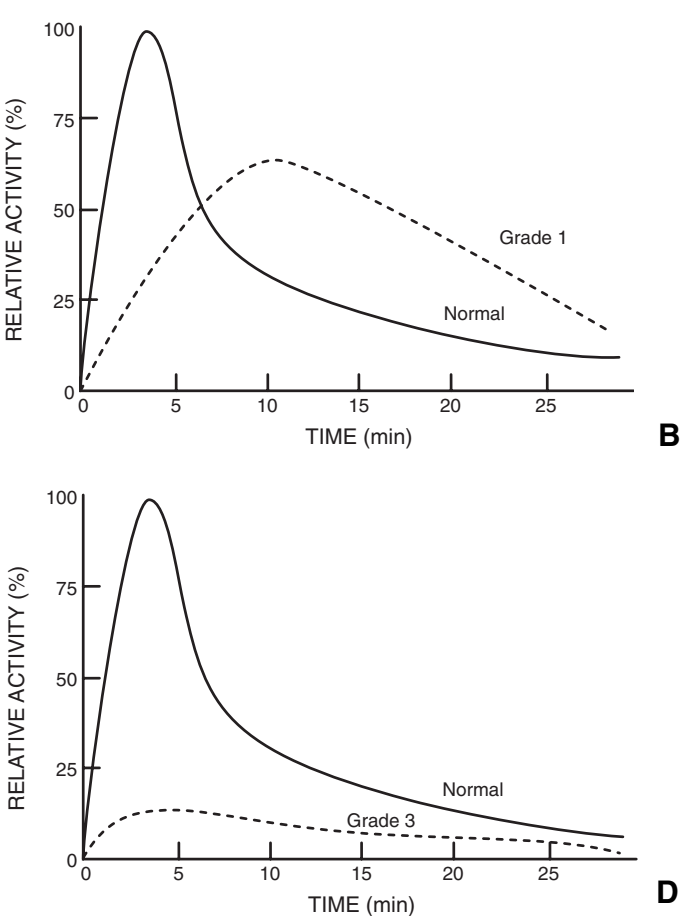

Fig. 4 Renogram grading. (A) Grade 0: Normal renogram with a normal time to peak activity. (B) Grade 1: Mild delay to peak activity with excretory phase. (C) Grade 2A: Prolonged delay in upstroke with excretory phase; Grade 2B: Prolonged delay in upstroke without excretory phase. (D) Grade 3: Marked reduction or absence of uptake. Reproduced with permission from Nally JV, Chen C, Fine E, et al. Diagnostic criteria of renovascular hypertension with captopril renography—a consensus statement. AJH 4:S749-S752

the statistical merit of CRS as a screening test. ${ }^{8,25-31}$ Later studies focused on the prospective evaluation of CRS and its value in outcome prediction. ${ }^{8,29,32-35}$ With the consensus conference statement, many of the proce-

Table 11 Probability of RAS Based on Grading Before and After Captopril

\begin{tabular}{llllll}
\hline & \multicolumn{5}{c}{ After Captopril } \\
\cline { 2 - 6 } Baseline & 0 & $\mathrm{I}$ & $2 \mathrm{~A}$ & $2 \mathrm{~B}$ & 3 \\
0 & $\mathrm{~L}$ & $\mathrm{H}$ & $\mathrm{H}$ & $\mathrm{H}$ & $\mathrm{H}$ \\
$\mathrm{l}$ & $\mathrm{L}$ & $\mathrm{I}$ & $\mathrm{H}$ & $\mathrm{H}$ & $\mathrm{H}$ \\
$2 \mathrm{~A}$ & $\mathrm{~L}$ & $\mathrm{~L}$ & $\mathrm{I}$ & $\mathrm{H}$ & $\mathrm{H}$ \\
$2 \mathrm{~B}$ & $\mathrm{~L}$ & $\mathrm{~L}$ & $\mathrm{~L}$ & $\mathrm{I}$ & $\mathrm{H}$ \\
3 & $\mathrm{~L}$ & $\mathrm{~L}$ & $\mathrm{~L}$ & $\mathrm{I}$ & $\mathrm{I}$ \\
\hline
\end{tabular}

$\mathrm{L}=$ Low probability; $\mathrm{I}=$ Indeterminant $\mathrm{H}=$ High.

Reproduced with permission from Nally JV, Chen C, Fine E, et al. Diagnostic criteria of renovascular hypertension with captopril renography—a concensus statement. AJH 1991;4:S749-S752 

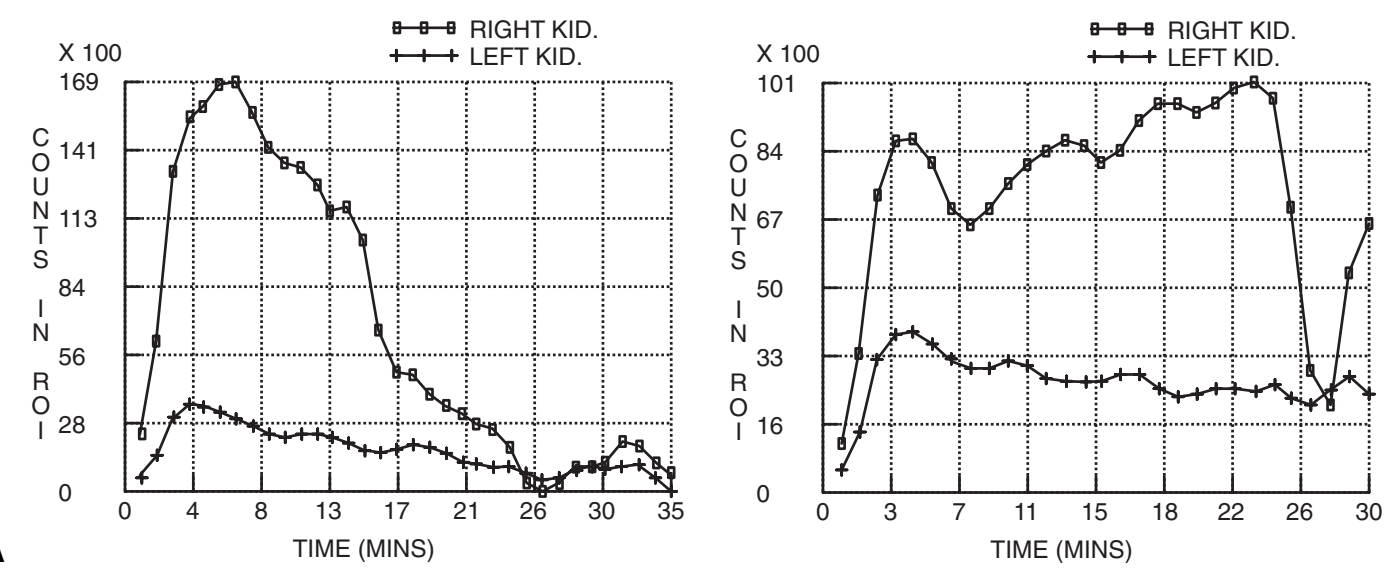

B

Fig. 5 Abnormal Renogram. (A) Before captopril (B) After captopril. Increased time to peak activity is seen in the right kidney. (C) Angiogram demonstrating right sided renal artery stenosis at origin.

dural aspects of the CRS as outlined above are now standardized. Despite this and the recognition that CRS has a reasonably high sensitivity, specificity, and predictive value for renovascular hypertension when applied to a high-risk population, CRS remains underutilized. Continued research efforts are underway to determine the utility of CRS in screening patients with bilateral disease, renal artery stenosis in the setting of a single kidney, and in patients with renal dysfunction. The advantage of combining anatomic and functional testing into a single modality has stimulated interest in the administration of captopril in conjunction with ultrasound or magnetic resonance imaging. The early results with CRS have been reviewed previously. ${ }^{10,21,41,42}$ We will review here the current status and address the remaining unresolved issues.

The primary controversy focuses on whether CRS can effectively distinguish renal artery stenoses that are clinically significant from those that are 
not. The reported sensitivities and specificities of CRS as a screening tool are widely variable. With contrast angiography remaining the gold standard, the degree of stenosis associated with a positive CRS scan has ranged from 50 to $70 \%$. A recent retrospective review by Van Jaarsveld et al. applied CRS to 505 high-risk patients defining a greater than $50 \%$ stenosis as critical. ${ }^{43}$ The objective of this study was primarily to compare radiopharmaceuticals DTPA versus MAG3 in screening for renal artery stenosis. The sensitivity achieved when the specificity was set to $90 \%$ was only $68 \%$. Screening for anatomic disease alone ignores the basic principle of CRS, that is, only the presence of a hemodynamically significant renal artery lesion will produce the alterations of the renin-angiotensin-aldosterone axis in response to captopril necessary to produce a positive renogram. There is, however, no consensus as to what constitutes a hemodynamically -significant stenosis. Further confusing the matter is the fact that interventions for even higher-grade stenoses may not consistently produce an improvement in blood pressure control. ${ }^{30}$ However, it is uncertain how much of this reflects a failure of the intervention versus the functional insignificance of the lesion. Furthermore between 10 and 20\% of patients with angiographically identified RAS and negative functional testing may still exhibit some degree of improvement with intervention. ${ }^{8}$

Higher degrees of arterial narrowing, nevertheless, are more likely to be functional and studies that have used more stringent criteria have demonstrated an improved sensitivity and specificity for the use of CRS in screening for both the presence of stenosis and renovascular hypertension. In the studies from Yale, criteria for a significant angiographic lesion were set to either $>75 \%$ narrowing or between 50 and $75 \%$ narrowing associated with a poststenotic dilatation. ${ }^{8,32-34}$ With these criteria, sensitivities and specificities of $91 \%$ and $87 \%$ for a diagnosis of renal artery stenosis and $80 \%$ and $85 \%$ for a diagnosis of renovascular hypertension were obtained. In the final report of the European multicenter trial, Fommei et al. using a greater than $70 \%$ stenosis as a criterion for a significant lesion, cites a sensitivity and specificity of $83 \%$ and $93 \%$ for the detection of RAS, and $93 \%$ and $100 \%$ for renovascular hypertension (with normal renal function) in spite of variability in technique from the participating institutions. ${ }^{44}$ Likewise, Mann et al. using a criterion of greater than $70 \%$, obtained high values for sensitivity (94\%) and specificity (95\%) to differentiate patients with RAS from those with essential hypertension utilizing both captoprilassociated renogram changes and three parameters of functional asymmetry from side to side ${ }^{45}$ As part of a recent cost analysis evaluating CRS, angiography, and duplex scanning as a screening test, Blaufox et al. performed a metaanalysis of the major studies to calculate overall sensitivities and specificites for CRS in diagnosing RAS and RVH. Values of sensitivity and specificity for RAS and $\mathrm{RVH}$ were $89 \%$ and $92 \%$ and $92 \%$ and $86 \%$, respectively. 46

A recent update of the Albert Einstein-Cornell collaborative group by Blaufox et al. reported on a prospective analysis that included CRS testing on both a low-risk and high-risk population for renovascular hypertension and 
simultaneously compared the use of a tubular (OIH) and glomerular (DTPA) agent with results compared by both quantitative and qualitative CRS means. ${ }^{40}$ Their findings confirmed previous reports of no difference between strict quantitative analysis and qualitative inspection of the renogram curve, and they found no statistically significant difference between the use of a glomerular versus tubular agent. The tubular agent did, however, appear more accurate in patients with renal dysfunction. None of the patients in the low-risk category had a positive test and none underwent angiography. In the high-risk group, the determination of sensitivity and specificity for renal artery stenosis $>50 \%$ was confounded by the large number of abnormal, nondiagnostic tests $(29 / 60)$. This difficulty was attributed to the high percentage of patients with bilateral disease $(37 \%)$ and reduced renal function (GFR less than $50 \mathrm{~mL} / \mathrm{min}$ ) in $27 \%$ of the patients. They note, however, there were few false positive $(5 \%)$ examinations.

In many hypertensive patients with renovascular disease, the renal artery stenoses are bilateral and are more likely to be associated with renal dysfunction. ${ }^{6}$ The rate of bilaterality in these radionuclide studies varies and has been reported as high as $40 \%$ in the populations studied. ${ }^{28,40}$ Although identification and successful revascularization may improve blood pressure control, the primary objective of intervention is increasingly focused on stabilizing or improving renal function. In view of the progressive nature of the atherosclerosis, these patients (especially if their hypertension is satisfactorily controlled) may not be identified until renal failure precipitates the need for dialysis. It is estimated that up to $15 \%$ of patients who present for dialysis with end-stage renal disease may have a renovascular etiology of their renal failure. ${ }^{47}$ One of the criticisms of CRS has been its inability to accurately identify this subset of the hypertensive population. While the glomerular agent, [ $\left.{ }^{99 \mathrm{~m} T \mathrm{c}}\right] \mathrm{DTPA}$, is recognized to have diagnostic limitations in the face of significant renal cortical dysfunction, the efficacy and safety of DTPA renography in screening patients with a creatinine $<2.5$ has been reported by multiple groups. $8,31,32,48$ The consensus group recommended great care in the use of this agent in patients with a creatinine $>2.5$ and not at all for those with a creatinine $>5.0 .4^{49}$ Overall, when applied to patients with bilateral disease, CRS sensitivity decreases slightly, however, these differences may be more related to coexisting renal functional impairment. $8,26,31,45,48$ As in experimental bilateral renal artery stenosis, the hypertension may in part be due to volume expansion suppressing intrarenal renin (especially on the side of the less severe stenosis), resulting in an absence of captopril-related changes on that side and what may appear as a unilateral stenosis may, in fact, be bilateral. 8,35 The functionality of these stenoses may not be prospectively determined and the inability to treat both stenoses simultaneously may also contribute to a lower sensitivity.

The most recent advance with respect to methodology has been the introduction and prospective analysis of [ $\left.{ }^{99 \mathrm{~m} T \mathrm{~T}}\right] \mathrm{MAG} 3$ as a radiopharmaceutical 
agent in CRS. MAG3 renography has been demonstrated to be at least equivalent to DTPA and appears to be less renal-toxic. ${ }^{50-52}$ A recent study by Roccatello et al. evaluated 29 patients with RAS > 50\% with MAG3 renography using a new method utilizing a calculated theoretical contralateral curve called the 'expected renogram' to eliminate the need to calculate relative differences between kidneys. ${ }^{54} \mathrm{~A}$ difference of more than two standard deviations between the expected and recorded curves was taken as a positive scan. An increase in specificity from 70 to $95 \%$ using this method with no change in sensitivity $(79.3 \%)$ was seen. Fourteen of eighteen patients with positive studies achieved long-term benefit from intervention.

While a renal artery stenosis is suspected primarily because of the identification of a hypertensive patient at risk, a subset of patients will have renal impairment, which may be attributable to a renal artery lesion, without associated hypertension. Patients with ischemic nephropathy are at risk for renal loss and may benefit from renal revascularization on the basis of renal functional deterioration alone. Rapid deterioration of renal function over a short period of time often precipitated by a reduction in blood pressure, usually in an elderly patient (especially in the face of generalized atherosclerosis) is likely renovascular in origin. ${ }^{3,54} \mathrm{~A}$ study to assess the value of CRS in this population of patients has yet to be undertaken.

The role of CRS in the evaluation of patients with renovascular hypertension and a solitary kidney is poorly defined. While experimental models of RAS in a solitary kidney support a volume-dependent as opposed to renindependent mechanism for hypertension, captopril-associated changes in the renogram have been reported by Fanti et al. and ameliorated with intervention. ${ }^{55}$ In this series of 12 patients, CRS was performed with [99mTc]MAG3 and identified all patients with a RAS $>50 \%$ with only one false negative. Quantitative parameters were examined in the absence of an overt change in the shape of the renogram. While only three of six patients with positive CRS underwent intervention, each demonstrated cure or improvement. Administration of captopril was associated with a modest decrease in blood pressure but no serious side effects.

The recognized limitations of CRS along with the advantages of coupling anatomic imaging with functional assessment in the diagnosis of renovascular hypertension has stimulated interest in identifying captopril-induced alterations that may be observed with other imaging modalities, specifically ultrasound and magnetic resonance imaging.

The use of duplex ultrasonography in the evaluation of renovascular pathology is well recognized with established criteria to suggest the presence of renal artery stenosis. A renal artery peak systolic velocity (RA-PSV) $>210$ $\mathrm{cm} / \mathrm{s}$ and a ratio of the renal artery peak systolic velocity to aortic peak systolic $(\mathrm{RAR})>3.5$ is associated with reasonably high sensitivity and specificity though the percentage of inadequate exams ranges between 10 and 30\%. 3,56 Duplex examination of the parenchymal vessels may increase the number of 
technically satifactory studies. Duplex parameters such as the resistive index $(\mathrm{RI}),(\mathrm{RI}=$ [peak systolic velocity - end diastolic velocity] / peak systolic velocity), and acceleration time in early systole slope of waveform upstroke can be measured with an $\mathrm{RI}<0.7$ and delayed acceleration indicative of renal artery stenosis, although results are varied. ${ }^{56,57}$ Recently, significant alterations in these duplex parameters with the administration of captopril have been demonstrated and shown to correlate with both CRS and angiographically demonstrated renal artery stenoses. The predictive value of these changes, however, remains to be determined in large series.

Gottlieb et al. further exploring the utility of ultrasound, determined the change in resistive index in 39 patients suspected of having renovascular hypertension and compared the results with those of captopril renography. ${ }^{57}$ In those patients with a positive captopril renogram, a significant difference between the resistive index from one side to the other was seen after captopril administration. Threshold values after captopril that resulted in optimal sensitivity and specificity in determining the presence of a renal artery stenosis $>50 \%$ are given as follows: difference between resistive index from side to side $(\mathrm{DRI})>0.10$, smallest of the two resistive indices $(\mathrm{RI})<0.55$ and difference in kidney length from side to side $(\mathrm{dL})>2.0 \mathrm{~cm}$.

In a more recent study, Oliva et al. in an extension of an earlier study assessed 135 kidneys in 71 hypertensive patients by transrenal Doppler sonography with 96 kidneys studied before and after the administration of captopril.58 All patients subsequently underwent contrast angiography. The authors demonstrated an increased sensitivity and specificity for the diagnosis of a renal artery stenosis following the administration of captopril. An acceleration threshold of $390 \mathrm{~cm} / \mathrm{sec}^{2}$ was associated with a sensitivity of $77 \%$ and specificity of $93 \%$ for a RAS > 50\% before the administration of captopril whereas, after the administration of captopril, an acceleration threshold of $440 \mathrm{~cm} / \mathrm{sec}^{2}$ had a sensitivity and specificity of $100 \%$ and $94 \%$, respectively. The area under the receiver-operator characteric (ROC) curve was significantly improved with the administration of captopril increasing from 0.8836 to 0.9847 ( $\mathrm{p}=0.009$ ).

Reported technical failure rates for the use duplex ultrasonography in the diagnosis of renal artery stenosis have been reported to be as high as $15 \%$ primarily due to overlying bowel gas obscuring the sonographic view of the main renal artery. ${ }^{59}$ With renal parenchymal imaging this is less of a consideration, however, segmental stenoses may be missed because of limited sampling. This difficulty is also present with CRS because of the limited resolution of nuclear scintigraphy. In the continued search for functional studies that provide good anatomic detail, interest in identifying captoprilinduced alterations associated with gadolinium enhanced MR imaging has increased.

In a rat model of renovascular hypertension, Trillaud et al. demonstrated captopril-induced MR gadolinium tubular transit asymmetry. ${ }^{60}$ Based on this 
work, Grenier et al. evaluated 15 patients with angiographically confirmed renal artery stenosis by captopril-sensitized dynamic MR imaging. ${ }^{61}$ The study was repeated without captopril in the face of asymmetric renal MR signal intensity. Standard CRS and MR angiography were also performed on each patient for the purposes of comparison. Four of the 15 patients demonstrated captopril-associated changes on MR that correlated with the findings of CRS. One additional patient identified by MR but not by CRS had a stenosis of an upper pole renal artery perhaps caused by the better spatial resolution of MR. In this study, MR angiography was also compared with standard angiography but failed to demonstrate the renal artery lesion in one third of the cases. Interventions were performed on ten patients of which seven demonstrated cure or improvement. With the exception of one technical failure, each of these patients was cured or improved with intervention with two demonstrating normalized intrarenal kinetics on repeat MR imaging. Interestingly, four patients with both negative CRS and negative MR studies were clinically cured or improved with intervention.

Unfortunately, the passage of the MR contrast agent is dependent on renal function and this method is limited in the presence of significant renal dysfunction and its utility in bilateral disease remains in question. MR renography does, however, have better spatial resolution than standard renography and may delineate parenchymal alterations associated with a segmental renal artery lesion. Standard contrast angiography remains, however, the gold standard because of its superior ability to demonstrate arterial lesions into the segmental branches.

\section{COST CONSIDERATIONS AND RECOMMENDATIONS}

Multiple factors define the context for selecting a study to document renovascular hypertension: patient demographics, symptom severity, the risk/benefit considerations of intervention, the presence of renal dysfunction, and expense. Blaufox et al. performed a cost analysis based on sensitivity, specificity and predictive values obtained through metaanalyses for captopril renal scintigraphy, duplex ultrasonography, and angiography for both renal artery stenosis and renovascular hypertension. ${ }^{46}$ The values obtained are tabulated for each modality in Table 4 . These statistical values were applied to a hypothetical population of 1000 patients to assess the cost effectiveness of each modality in screening for renovascular hypertension. The combined cost of the screening process plus the cost of intervention with a $77 \%$ cure or improvement rate was compared to the cost of two- and three-drug medical therapy for this hypothetical population over a fixed life expectancy of 20 years. The costs associated with the complications of angiography, hypertension, medication, lab tests, or an outcome that might include dialysis-dependence were not included, however, the cost of the complications of angioplasty or surgery were included. Screening for renovascular hyperten- 
sion under these hypothetical conditions was not found to be cost-effective only for a prevalence rate for renovascular hypertension of $<30 \%$. Angiography and CRS, under the study conditions, were found to be equally costeffective in screening for RAS with CRS at a slight advantage over angiography in screening for $\mathrm{RVH}$, with angioplasty (not surgery) as an intervention. It is important to note that the $77 \%$ cure or improvement rate was based on angioplasty data for all patients treated with a RAS $>50 \%$, once again emphasizing that treatment of anatomic lesions will be of no benefit approximately one quarter of the time. In the context of a high-risk patient population undergoing high-risk procedures, this represents a particular problem. Functional testing with CRS improves the interventional success rate to at least $85 \%$ and may alter the analysis in its favor. ${ }^{8}$ CRS screening additionally has the potential to eliminate the need for angiography in some patients with a consequent cost savings. Duplex ultrasonography was not found to be cost-effective and was associated with a high technical failure rate; it is likely, however, that the improvement in sensitivity, specificity, and technical success rates with parenchymal and captopril scanning techniques may improve its value as a screening method.

In a younger patient population the prevalence of renovascular hypertension is low but the risk of disease rises to a high level on the basis of clinical criteria alone. A screening examination under this circumstance should exhibit a high sensitivity to ensure that all patients with disease are identified and appropriately treated. In a population in which FMD is more likely to be the cause of renovascular hypertension, angiography with its potential for immediate intervention should be the screening modality of choice. In the older population in which atherosclerosis prevails, the risks associated with an invasive screening method are increased and the risk of screening versus the benefit of intervention is less clear-cut. A screening test with a high specificity and predictive value is required to limit the number of patients who would be exposed to an intervention from which they would not benefit. In this circumstance, CRS seems to be a more rational choice. Patients with negative scans would be spared the risks associated with angiography. Patients with a high suspicion for disease in spite of a negative CRS should undergo either repeat CRS or angiography to rule out segmental stenosis or stenosis of an accessory renal artery. The role of duplex ultrasonography and standard MR angiography is less clear at this time, however, they may be useful as an initial screening tests in patients with impaired renal function (creatinine > 3.0). These non-invasive tests may identify pathology not amenable to revascularization without subjecting the patient the risk of angiography. On the other hand, should a renovascular lesion be identified with an intervention likely to be beneficial, then further work-up can proceed.

A significant difficulty is assessing the efficacy of CRS when posttreatment outcome is associated with neither a cure nor improvement of blood pressure. Does this represent a testing failure or a technical failure? Few studies 
have correlated clinical outcomes with postintervention CRS results. Such studies might elucidate the cause of treatment failures and confirm the efficacy of successful intervention.

\section{SUMMARY}

In summary, renal artery stenosis is an anatomic diagnosis and is to be differentiated from renovascular hypertension or ischemic nephropathy, which are retrospective diagnoses, based on the outcome following a technically successful revascularization. ACE inhibition induces physiologic alterations that may be detected via radionuclide scintigraphy or more recently ultrasound and magnetic resonance imaging. The safety and efficacy of CRS has been demonstrated in renovascular hypertension and in spite of a $>90 \%$ positive predictive value, remains underutilized in screening high-risk patients. The potential to couple more complete anatomic with physiologic information in a single screening method such as in captopril sonography and captopril MR is attractive although the efficacy and predictive value of these methods have yet to be validated in large clinical trials.

\section{REFERENCES}

1. Hricik DE, Browning PJ, Kopelman R, et al. Captopril-induced functional renal insufficiency in patients with bilateral renal artery stenoses or renal artery stenosis in a solitary kidney. N Engl J Med 1983;308:373-376

2. Black HR, Nally JV. Introduction to the supplement of the American Journal of Hypertension-captopril renal scintigraphy. AJH 1991;4:S661-S662

3. Dean RH, Hansen K. Renovascular hypertension. In: Moore WS, ed. Vascular SurgeryA Comprehensive Review. Philadelphia, PA: W.B. Saunders; 1998:521-541

4. Elliott WJ, Toth SJ, Stemer A, et al. Detection, treatment and control of adult hypertension in northwest Indiana. AJH 1999;12:830-834

5. King BF. Diagnostic imaging evaluation of renovascular hypertension. Abdominal Imaging $1995 ; 20: 395-405$

6. Eyler WR, Clark MD, Garman JE, et al. Angiography of the renal areas including a comparative study of renal arterial stenoses in patients with and without hypertension. Radiology 1962;78:879-892

7. Schreiber MJ, Pohl MA, Novick AC. The natural history of atherosclerotic and fibrous renal artery disease. Urologic Clinics of North America 1984;11:383-392

8. Setaro JF, Saddler MC, Chen CC, et al. Simplified captopril renography in diagnosis and treatment of renal artery stenosis. Hypertension 1991;18:289-298

9. Sox HC. Probability theory in the use of diagnostic tests. Ann Int Med 1986;104:60-66

10. Nally JV. Provocative testing in the diagnosis of renovascular hypertension. Urol Clini $\mathrm{N}$ Amer 1994;21:227-234

11. Vidt DG. The diagnosis of renovascular hypertension-a clinician's viewpoint. AJH 1991;4:S663-S668

12. Sarkar R, Messina L. Pathology of renal artery occlusive disease. In: Ernst C, Stanley J, eds. Current Therapy in Vascular Surgery. St Louis, MO: Mosby; 1995:764-768

13. Harrison EG, McCormack LJ. Pathologic classification of renal arterial disease in renovascular hypertension. Mayo Clinic Proc 1971;46:161-167 
14. Grim CE, Luft FC, Weinberger HM, et al. Sensitivity and specificity of screening tests for renal vascular hypertension. Ann Int Med 1979;91:617-622

15. Davis BA, Crook JE, Vestal RE, et al. Prevalence of renovascular hypertension in patients with grade III or IV hypertensive retinopathy. N Engl J Med 1979;301:1273-1276

16. Goldblatt H, Lynch J, Hanzel RF, et al. Studies on experimental hypertension-the production of persistent elevation of systolic blood pressure by means of renal ischemia. J Exp Med 1934;59:347-379

17. Stanton BA, Koeppen BM. Control of body fluid osmolality and volume. In: Berne RM, Levy MN, eds. Physiology. St Louis, MO: Mosby; 1993:719-753

18. Hall JE, Guyton AC, Jackson TE, et al. Control of glomerular filtration rate by reninangiotensin system. Am J Physiol 1977;233:F366-F372

19. Ploth D. Angiotensin-dependent renal mechanisms in two-kidney, one-clip renal vascular hypertension. Am J Physiol 1983;245:F131-F141

20. Anderson WP, Denton KM, Woods RL, et al. Angiotensin II and the maintenance of GFR and renal blood flow during renal artery narrowing. Kid Intl 1990;39:S109-S113

21. Nally JV, Black HR. State of the art review: captopril renography-pathophysiological considerations and clinical observation. Sem Nucl Med 1992;22:85-97

22. Fanti S, Dondi M, Corbelli C, et al. Evaluation of hypertensive patients with solitary kidney using captopril renal scintigraphy with ${ }^{99 m T c-M A G 3 . ~ N u c l ~ M e d ~ C o m m ~ 1993 ; 14: ~}$ 969-975

23. Working group on renovascular hypertension. Detection, evaluation and treatment of renovascular hypertension. Arch Int Med 1987;147:820-829

24. Majd M, Potter BM, Guzetta PC, Rutery ES, et al. Effect of captopril on efficacy of renal scintigraphy in detection of renal artery stenosis. J Nucl Med 1983;24:23

25. Geykses GG, Oei HY, Puylaert BAJ, Mees EF. Renovascular hypertension identified by captopril-induced changes in the renogram. Hypertension 1987;9:451-458

26. Sfafianakis GN, Bourgoignie JJ, Jaffe D, et al. Single dose captopril scintigraphy in the diagnosis of renovascular hypertension. J Nucl Med 1987;28:1383-1392

27. Svetkey LP, Himmelstein SI, Dunnick R, et al. Prospective analysis of strategies for diagnosing renovascular hypertension. Hypertension 1989;14:247-257

28. Dondi M, Franchi R, Levorato M, et al. Evaluation of hypertensive patients by means of captopril enhanced renal scintigraphy with 99mTc-DPTA. J Nucl Med 1989;30:615-621

29. Postma CT, Aernout HAM, Barentsz J, et al. The value of test predicting renovascular hypertension in patients with renal artery stenosis treated by angioplasty. Arch Int Med 1991;151:1531-1535

30. Fine EJ. The Einstein/Cornell Collaborative protocol to assess efficacy and methodology in captopril scintirenography. AJH 1991;4:S716-S720

31. Fommei E, Mezzasalma L, Ghione S, et al. European captopril radionuclide test multicenter study-preliminary results. AJH 1991;4:S690-S697

32. Meier GH, Sumpio B, Black HR, Gooseberry RJ, et al. Captopril renal scintigraphy-An advance in the detection and treatment of renovascular hypertension. J Vasc Surg 1990;11:770-777

33. Setaro JG, Chen C, Hoffer PB, et al. Captopril renography in the diagnosis of renal artery stenosis and the prediction of improvement with revascularization. J Hypertens 1991;4:S698-S704

34. Meier GH, Sumpio B, Setaro JF, et al. Captopril renal scintigraphy: a new standard for predicting outcome after renal revascularization. J Vasc Surg 1993;17:280-287

35. Geykses GG, Bruyn AJ. Captopril renography and the effect of percutaneous transluminal angioplasty on blood pressure in 94 patients with renal artery stenosis. AJH 1991;4:S685-S689

36. Mettler FA, Guiberteau MJ. Genitourinary system. In: Essentials of Nuclear Imaging. Philadelphia, PA; W.B. Saunders; 1998:335-368 
37. Dondi M, Monetti N, Fanti S, et al. Use of $99 \mathrm{mTc}-M A G 3$ for renal scintigraphy after angiotensin-converting enzyme inhibition. J Nucl Med 1991;32:424-428

38. Oei HY. Captopril Renography-early observations and diagnostic criteria. AJH 1991;4:S678-S684

39. Nally JV, Chen C, Fine E, et al. Diagnostic criteria of renovascular hypertension with captopril renography-a consensus statement. AJH 1991;4:S749-S752

40. Blaufox DM, Fine E, Hurley J, et al. Prospective study of simultaneous orthoiodohippurate and diethylenetriaminepentaacetic acid captopril renography. J Nucl Med 1998;39:522-528

41. Davidson R, Wilcox CS. Diagnostic usefulness of renal scanning after angiotensin converting enzyme inhibitors. Hypertension 1991;18:299-303

42. Dondi M, Fanti S, Monetti N. Captopril renal scintigraphy: a viewpoint. J Nucl Med Biol 1993;37:259-263

43. VanJaarsveld BC, Krijen P, Derkx FHM, et al. The place of renal scintigraphy in the diagnosis of renal artery stenosis. Arch Int Med 1997;157:1226-1234

44. Fommei E, Ghione S, Hilson AJW, et al. Captopril radionuclide test in renovascular hypertension: a European multicenter study. Eur J Nucl Med 1993;20:617-623

45. Mann SJ, Pickering TG, SOS TA, et al. Captopril renography in the diagnosis of renal artery stenosis: accuracy and limitations. Am J Med 1991;90:30-40

46. Blaufox MD, Middleton ML, Bongiovanni J, et al. Cost efficacy of the diagnosis and therapy of renovascular hypertension. J Nucl Med 1996;37:171-177

47. Rimmer JM, Gennari FJ. Atherosclerotic renovascular disease and progressive renal failure. Ann Int Med 1993;118:712-719

48. Scoble JE, McClean A, Stansby G, et al. The use of captopril-DPTA scanning in the diagnosis of atherosclerotic renal artery stenosis in patients with impaired renal function. AJH $1991 ; 4: S 721-S 723$

49. Blaufox DM, Dubovsky EV, Hilson, AJW. Report of the working party group on determining the radionuclide of choice. AJH 1991;4:S747-S748

50. Taylor A, Ziffer JA, Steves A, et al. Clinical comparison of I-131 orthoiodhippurate and the kit formulation of ${ }^{99 m}$ Tc-Mercaptoacetyltriglycine. Radiology 1989;170:721-725

51. Russell CD, Thorstad B, Yester M, et al. Comparison of 99mTc-MAG3 with Iodine-131 Hippuran by a simultaneous dual channel technique. J Nucl Med 1988;29:1189-1193

52. Dondi M, Monetti N, Fanti S, et al. Use of $99 \mathrm{~m} T \mathrm{Tc}-\mathrm{MAG} 3$ for renal scintigraphy after angiotensin-converting enzyme inhibition. J Nucl Med 1991;32:424-428

53. Roccatello D, Picciotto G. Captopril-enhanced scintigraphy using the method of the expected renogram: improved detection of patients with renin-dependent hypertension due to functionally significant renal artery stenosis. Neph Dial Transplant 1997;12: 2081-2086

54. Jacobson HR. Ischemic renal disease: an overlooked clinical entity. Kidney International 1988;34:729-743

55. Fanti S, Dondi M, Corbelli C, et al. Evaluation of hypertensive patients with a solitary kidney using captopril renal scintigraphy with 99mTc-MAG3. Nucl. Med Comm 1993;14:969-975

56. Miralles M, Sanitso A, Gimenez V, et al. Renal duplex scanning: correlation with angiography and isotopic renography. Eur J Vasc Surg 1993;7:188-194

57. Gottlieb RH, Lieberman JL, Ghaed VN, et al. Preliminary assessment of captopril sonography in screening for renal artery stenosis. Acad Radiol 1995;3:57-62

58. Oliva V, Gilles S, Lesage D, et al. Detection of renal artery stenosis with Doppler sonography before and after administration of captopril: value of early systolic rise. AJR 1998;170:169-175

59. Kaplan-Pavlovcic S, Chwatal N. Captopril renography and duplex Doppler sonography in the diagnosis of renovascular hypertension. Neph Dial Trans 1998;13:313-317 
60. Trillaud H, Roques F, Degreze P, et al. Angiotensin-converting enzyme inhibitor-induced MR gadolinium tubular transit asymmetry in experimental renovascular hypertension. J Magn Reson Imaging 1996;6:149-155

61. Grenier N, Trillaud H, Combe C, et al. Diagnosis of renovascular hypertension: feasibility of captopril-sensitized dynamic MR imaging and comparison with captopril scintigraphy. AJR 1996;166:835-843 
The authors present an excellent review of captopril renography and its use in the evaluation of renovascular hypertension. The primary objective of a noninvasive test should be the identification of hypertensive patients who have "clinically significant" renal artery stenosis and to predict those most likely to benefit from surgical or endovascular repair with improvement in blood pressure or renal function.

There are a number of commonly used imaging modalities that can document the presence and significance of a renal artery stenosis, including Duplex ultrasound and MR angiography. The captopril renogram has the unique attribute of providing functional assessment of renal perfusion. In patients with normal renal function and unilateral renal artery disease, the test has achieved an enviable sensitivity and specificity reported up to $100 \%$ in selected high prevalence patient populations. However, it is limited by poor specificity in those with chronic renal insufficiency, a single kidney, and in patients with bilateral renal artery stenoses. Another major limitation is the need to stop converting enzyme inhibitors, and sometimes diuretics and calcium blockers before the test.

Noninvasive testing should be reserved for those patients with a high clinical suspicion of renovascular disease. In some it may be more cost effective to proceed directly to angiography, especially if the patient is a candidate for endovascular intervention. Several recent studies suggest that screening tests are unnecessary, as clinical clues are just as accurate as the captopril renogram. ${ }^{1}$

Today the challenge in renovascular disease is to predict those patients who may benefit from renal artery revascularization. A recent multicenter randomized trial had disappointing results and could not show any overall benefit of renal artery angioplasty over medical management. ${ }^{2}$ Clearly, this is a failure to properly select those patients most likely to benefit from revascularization. We are still awaiting the ideal test to identify these patients.

\section{REFERENCES}

1. Krijnen P, van Jaarssveld B, Steyerberg E, et al. A clinical prediction rule for renal artery stenosis. Ann Int Med 1998;129:705-711

2. Van Jaarsveld BC, Krijnen P, Pieterman H, et al. The effect of balloon angioplasty on hypertension in atherosclerotic renal-artery stenosis. NEJM 2000;442(14):1007-1014

R.F.J.S., Assistant Professor of Medicine; Consultant, Division of Hypertension and Division of Cardiovascular Medicine, Mayo Graduate School of Medicine; Mayo Clinic, Rochester, MN.

Copyright (C) 2000 by Thieme Medical Publishers, Inc., 333 Seventh Avenue, New York, NY 10001, USA. Tel. +1(212) 584-4662. 0894-8046,p; 2000,13,1,70.70,ftx,en; pvs00084A 